\title{
Aging and a benefit of distractibility
}

\author{
SUNGHAN KIM \\ University of Toronto, Toronto, Ontario, Canada \\ LYNN HASHER \\ University of Toronto, Toronto, Ontario, Canada \\ and Rotman Research Institute of Baycrest Centre, Toronto, Ontario, Canada \\ AND \\ Rose T. ZACKS \\ Michigan State University, East Lansing, Michigan
}

\begin{abstract}
Under instructions to ignore distraction, younger and older adults read passages with interspersed distracting words. Some of the distractors served as solutions to a subsequent set of verbal problems in which three weakly related words could be related by retrieving a missing fourth word (i.e., the Remote Associates Test [RAT]; Mednick, 1962). Older adults showed significant priming from the distraction, whereas younger adults did not. In this study, we present a case in which age-related reductions in attentional control over information that was not initially relevant can actually lead to superior performance for older adults. The RAT materials may be downloaded from www.psychonomic.org/archive.
\end{abstract}

It is not difficult to find evidence in the cognitive literature of age-related declines in various functions, including speed of processing, selective attention, working memory, long term memory, and problem solving (see, e.g., Craik $\&$ Salthouse, 2000; Park, 2000). There is some evidence suggesting that vulnerability to distraction is an important source of at least some of these age-related declines. Consider speed of processing. This fundamental aspect of cognition - which predicts a wide array of higher order cognitive abilities - has been widely reported to show substantial slowing across the adult life span (see, e.g., Fry \& Hale, 1996; Salthouse, 1996). Recent evidence suggests that one source of slowing is an age-related increase in distractibility (Lustig, Hasher, \& Tonev, 2006). In one experiment, Lustig et al. demonstrated that the presence of distraction, even in a very simple task such as comparing strings of letters, differentially impaired older adults relative to younger adults: The latter made comparisons equally quickly in the presence and in the absence of distraction.

Other evidence implicates susceptibility to concurrent distraction in the efficiency of problem solving (May, 1999). Using the Remote Associates Test (RAT; Mednick, 1962), in which participants are asked to link three very weakly related words (e.g., SHIP, OUTER, and CRAWL) by providing a missing fourth word (e.g., SPACE), May found that the presence of distraction had a substantially greater impact on older than on younger adults. In fact, under one circumstance (testing at a peak time of day), distraction had no effect on the performance of younger adults; it was as if it had not been present at all.
Although classic speed tasks such as letter comparison and classic problem solving tasks such as the RAT are very different in nature as well as in dependent measures, the impact of distraction on performance is the same: Older adults are differentially vulnerable to its presence. We note that the studies we have mentioned, as well as others in the attention and memory literature (e.g., Cohn, Dustman, \& Bradford, 1984; McDowd \& Oseas-Kreger, 1991; West, 1999), typically demonstrate the impact of distraction on a concurrent task.

Other evidence suggests that older adults are also differentially disrupted by target information presented in a previous task (see, e.g., May \& Hasher, 1998; May, Zacks, Hasher, \& Multhaup, 1999), which is consistent with the view that older adults have greater difficulty updating goals or suppressing no longer relevant information (see, e.g., Hasher, Lustig, \& Zacks, in press). Given evidence of older adults' greater sustained activation of information that is no longer relevant, we address a follow-up question: Is there a residual beneficial effect of the distraction encountered in one task on performance in a subsequent task?

To address the possibility of positive downstream consequences of distraction, we used the RAT to determine whether or not there might be an age-related benefit of sustained access to distraction presented in a previous task. To do this, we first asked participants to read stories with words embedded as distraction. This is a task in which older adults are differentially disrupted by concurrent distraction (see, e.g., Connelly, Hasher, \& Zacks, 1991; Duchek, Balota, \& Thessing, 1998; Dywan \& Murphy, 1996). The

S. Kim, shkim@psych.utoronto.ca 
reading task was followed 15 min later by the problem solving task, in which a proportion of items could be solved by words that had served as distractors in the earlier task. Our hypothesis was that, relative to younger adults, older adults would show greater benefit (or priming) from the reading task to the problem solving task, due to greater acquisition of information about the distractors while reading, prolonged activation of that information, or both.

\section{METHOD}

\section{Participants}

Twenty-six younger and 26 older adults participated in the experiment. We replaced participants who were aware of the connection between the reading-with-distraction task and the RAT task ( 7 younger adults and 1 older adult), participants who solved fewer than $10 \%$ of the RAT problems in any condition ( 1 younger adult and 3 older adults), and a participant who had had recent neurological problems ( 1 older adult). The mean age of the older adults was 68.5 years (range, 61-74), and that of the younger adults was 20 years (range, 18-23). The mean years of education was 16.4 (range, 12-20) for the older adults and 14.2 (range, 12-18) for the younger adults. The older adults had significantly higher vocabulary scores $(M=34.69)$ than younger adults $(M=20.37)[t(50)=6.5, p<.0001]$, as assessed by the Extended Range Vocabulary Test, Version 3 (Ekstrom, French, Harmon, \& Dermen, 1976). The younger adults received credit for an introductory psychology course, and the older adults received monetary compensation in return for their participation.

\section{Materials}

Five stories, averaging 127 words in length, were adapted from Connelly et al. (1991). One story served as a control for reading aloud without distraction, and the other four were experimental stories, all containing distracting words that were semantically unrelated to the target stories. Two sets of 16 critical words served as distractors, with 4 occurring in each test story. The four test stories included either one or the other set of distracting words, counterbalanced across participants. Within a story, each distractor occurred 15 times. The stories were printed in italics (in 12-point Courier New font), and the distracting words were printed in the standard form of the same font. The distracting words were never presented consecutively; they appeared at intervals of $1-5$ words of text. Each story was printed and presented on a sheet of $81 / 2 \times 11$-in. paper.

Each RAT problem consists of three cue words (e.g., ROOM, BUBBLE, SALTS). The task is to generate a word that links the three cue words (e.g., BATH). The task included a total of 50 RAT problems, all adapted from May (1999), Mednick (1962), and Smith and Blankenship (1991). Of these, 32 were critical problems, 16 of which could be solved by one (or the other) set of critical words that had served as distractors seen by half of the participants (target items) and 16 of which served as counterbalanced controls for the other set of distractors (control items). Thus, RAT problems whose solutions served as distractors in the reading-with-distraction task were target items, whereas those whose solutions did not appear as distractors in the previous task were control items. Also, 10 of the 18 filler RAT problems were selected to be particularly easy to solve so as not to discourage the participants. The RAT problems were presented in random order with the constraints that no more than two target problems could appear in a row, and when this occurred, their solutions did not come from the same story.

\section{Design and Procedure}

The design was a 2 (age: younger vs. older) $\times 2$ (item type: target vs. control) factorial design with age as a between-subjects variable and item type as a within-subjects variable.

The participants first read the distraction-free story aloud, followed by the four distraction stories in a fixed order. They were asked to read only italicized words and to ignore nonitalicized words. For each story, both reading time (calculated with a stop watch) and intrusions were recorded. The reading task was followed by unrelated, nonverbal filler tasks for $15 \mathrm{~min}$. The participants then received the RAT problems with instructions to generate a word that links the triplets. Following the procedure used by May (1999), each RAT problem appeared on a computer screen for $30 \mathrm{sec}$ or until the participant provided an answer. If no answer was generated, the next problem was displayed. If an answer was produced, regardless of its correctness, the experimenter pressed the space bar to advance to the next problem and recorded the response. At the completion of the task, the participants were questioned about whether they had noticed any connections between the first and the last tasks in the experiment. If they said yes, they were asked what and when they had noticed the connection and whether they had consciously tried to use or avoid using the distractors from the stories they had read as responses for the last task.

\section{RESULTS}

\section{Reading Time}

A preliminary analysis was conducted to check for replication of the basic reading-with-distraction finding that older adults are differentially slowed in the presence of distraction in text (see, e.g., Connelly et al., 1991; Duchek et al., 1998; Dywan \& Murphy, 1996). Reading time (in seconds) on the control story was first compared to the mean reading time for the four stories with distraction using a 2 (age: younger vs. older) $\times 2$ (story type: without vs. with distraction) ANOVA with age as a betweensubjects variable and story type as a within-subjects variable. The older adults were slower overall than the younger adults $[M \mathrm{~s}=79.22$ and $65.95 \mathrm{sec}$, respectively; $F(1,50)=$ $15.61, p<.0005],{ }^{1}$ the stories with distraction took longer to read than the story without distraction $[M \mathrm{~s}=81.49$ and $36.98 \mathrm{sec}$, respectively; $F(1,50)=371.42, p<.0001]$, and the absolute slowdown between the stories with and without distraction was greater for the older than for the younger adults $[F(1,50)=4.61, p<.05]($ see Table 1$)$.

In an additional analysis on reading time differences, we controlled for age-related differences in processing speed by using proportional reading times as a measure (see Duchek et al., 1998). The age $\times$ story type interaction reported above was no longer significant $[F(1,50)=$ $1.06, p=.31]$, nor was the main effect of age $[F(1,50)<$ 1]; only the main effect of story type was significant $[F(1,50)=895.39, p<.0001]$. Thus, the age $\times$ story type interaction in the initial analysis could be due to general age-related slowing rather than to age-related differences in susceptibility to distraction during reading.

\section{Accuracy on the RAT}

We used a 2 (age: younger vs. older) $\times 2$ (item type: target vs. control) ANOVA on percentage of problems solved to assess whether or not priming effects from the distraction in the stories varied with age. The critical interaction between age and item type was significant $[F(1,50)=$ $5.69, p<.05]$. As can be seen in Figure 1, the older adults showed a substantial benefit from exposure to distraction $[F(1,25)=7.12, p<.05]$ and the younger adults showed no effect of distraction $(F<1)$. There was no overall dif- 
Table 1

Mean Reading Times (in Seconds) and $S D$ s for Stories With and Without Distraction for Younger and Older Adults

\begin{tabular}{|c|c|c|c|c|}
\hline \multirow[b]{3}{*}{ Age } & \multicolumn{4}{|c|}{ Story Type } \\
\hline & \multicolumn{2}{|c|}{ Without Distraction } & \multicolumn{2}{|c|}{ With Distraction } \\
\hline & $M$ & $S D$ & $M$ & $S D$ \\
\hline Younger & 34.31 & 3.99 & 73.86 & 18.01 \\
\hline Older & 39.65 & 5.59 & 89.12 & 16.10 \\
\hline
\end{tabular}

ference in performance (measured in proportion of correct responses) on control RAT items between the younger and the older adults $[M \mathrm{~s}=.36$ and .37 , respectively; $t(50)=$ 0.36]. However, there was a significant difference for target RAT items between the younger and older adults $[M \mathrm{~s}=.34$ and .44 , respectively; $t(50)=2.98, p<.005]$. The older adults' problem solving clearly benefited from their greater access to distraction from the earlier task.

\section{Correlation Between Distraction Effect and Performance on the RAT}

A correlation analysis was performed to probe whether or not there was a positive relation between the effect of distraction during reading (mean target reading time minus mean control reading time) and later performance on the RAT (target items minus control items). This correlation was not significant $(r=-.04)$, suggesting that differential acquisition of information about distraction during reading may not be the source of age differences on RAT problems.

\section{DISCUSSION}

In the present study, we explored whether or not distraction that disrupts performance on one task can actually benefit performance on a quite different task when that distraction subsequently becomes relevant. For older adults, the answer is clearly that distraction can indeed benefit subsequent performance. The answer for younger adults is quite different; they showed no benefit from the distraction to which they were exposed in a previous task. This pattern thus resulted in a rare situation of superior performance by older adults.

What might account for this pattern of findings? We consider two possibilities: (1) age differences in initial activation or encoding of distracting words and (2) age differences in sustained activation of distracting words. According to the framework of Hasher, Zacks, and May (1999), inhibition serves to down-regulate the activation of nonrelevant information. Older adults, among others, are presumed to have reduced inhibitory efficiency. This reduction can enable more irrelevant information to enter focal attention under the first possibility and/or to remain continuously active even when tasks or goals change under the second. As a result, distraction can be expected to differentially impact older adults and others with inhibitory deficits (see, e.g., Hasher et al., 1999).

Our hypothesis that older adults would show greater initial activation to irrelevant words was based on pre- vious work (Connelly et al., 1991; Duchek et al., 1998; Dywan \& Murphy, 1996) showing that older adults are differentially slowed in their reading when passages contain distraction. This would allow for more words to be noted and encoded. However, we found neither readingwith-distraction effects over and above the general slowing that the older adults showed for the control passage nor evidence of a correlation between the degree to which individuals were slowed during reading and the degree to which they used the previous distractors as solutions to the verbal task. The failure to find the expected pattern of slowing and correlation effects might be taken as evidence against a differential encoding of distraction hypothesis, according to which older adults initially encode distraction more readily than younger adults. This conclusion would be consistent with the findings of Dywan and Murphy, who tested recognition of distraction from similar stories and found no evidence of superior recognition by older adults relative to younger adults.

The rejection of the initial encoding/activation hypothesis may be premature. For one thing, our measure of baseline reading speed may have been unstable given that we used a single no-distraction story as the control and others have used four to eight such stories. For another, there is substantial evidence elsewhere that older adults are less able to ignore concurrent distraction than are younger adults. May (1999) presented RAT triplets with and without distraction that was either related or unrelated to the solution. When the distraction was related to the solution, older adults showed greater benefits than did younger adults; when the distraction was unrelated, older adults showed greater disruption. Indeed, there were circumstances in May's study in which only older adults showed costs and benefits, suggesting that the regulation of attention at encoding varies with age and also that more distraction is encoded by older than by younger adults. Similarly, recent neuroimaging data suggest that

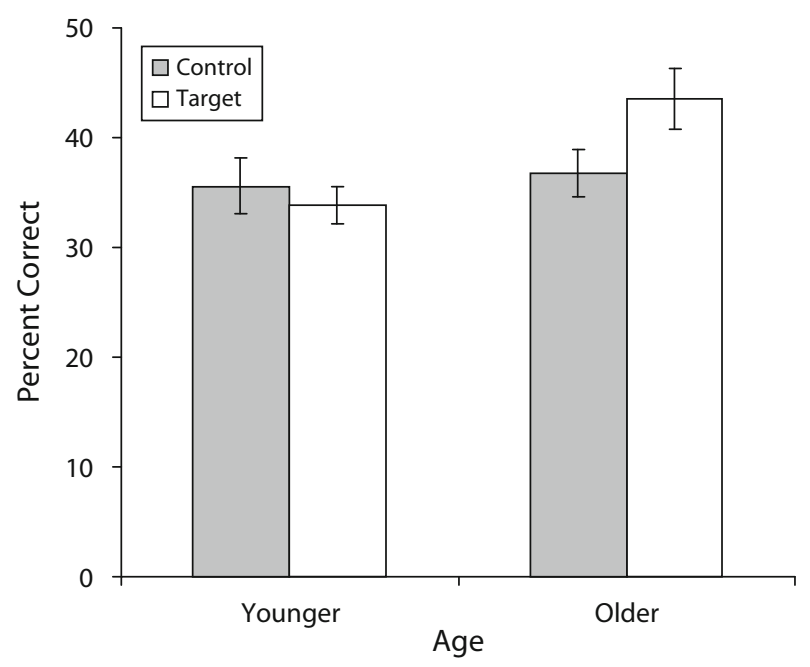

Figure 1. Mean percent correct scores for control and target RAT problems for younger and older adults. Error bars represent the standard error of the mean. 
older adults are less able to ignore a category (e.g., faces or scenes) of displays than are younger adults (see, e.g., Gazzaley, Cooney, Rissman, \& D’Esposito, 2005). Other evidence from the inference generation literature also suggests that older adults allow more irrelevant information to gain access to attention than do younger adults (Hamm $\&$ Hasher, 1992).

Still, there is no direct evidence in the present study of more distraction entering attention for older than for younger adults. The empirical evidence here is that older adults show substantial priming from distraction on one task in a subsequent problem solving task and that younger adults show none. On their own, those data can be accounted for by age-related differences in sustained activation of no longer relevant information, with no age-related difference in the amount of information initially encoded (see also Hamm \& Hasher, 1992; May et al., 1999).

The impact of irrelevant information on both a concurrent and a subsequent task depends on the relation between the irrelevant information and the task itself. In the literature, it is mostly the negative impact of concurrent distraction that has been studied, but there can be positive consequences as well, as has been shown here (see also May, 1999; Rowe, Valderrama, Hasher, \& Lenartowicz, 2006). The downstream effect reported here is a demonstration of the kind of "far transfer" effects widely sought after but rarely found in younger adults in the training and problem solving literature (see, e.g., Barnett \& Ceci, 2002).

The present findings are also relevant to creativity studies (e.g., Ansburg \& Hill, 2003). Our priming effect suggests that there are circumstances under which individuals with poor attentional control might be more creative than those who can better regulate their attention. In consistency with this inference, for example, Carson, Peterson, and Higgins (2003) demonstrated that reductions in the ability to screen out previously irrelevant stimuli from conscious awareness (called latent inhibition) is associated with increased creative thinking.

We note that our findings of superior performance by older adults stand in rather marked contrast to those typically reported in the cognitive aging literature, in which younger adults are virtually always at an advantage relative to older adults. Nonetheless, as many have pointed out (e.g., Adams, Smith, Pasupathi, \& Vitolo, 2002; Denney \& Pearce, 1989; Hess, Rosenberg, \& Waters, 2001; Labouvie-Vief, 1990), typical laboratory tasks may underestimate the true abilities of older adults, perhaps because materials and tasks are not engaging (see, e.g., May, Rahhal, Berry, \& Leighton, 2005), because instructions appropriate for younger adults are actually disruptive to older adults (see, e.g., Chasteen, Bhattacharyya, Horhota, Tam, \& Hasher, 2005), or perhaps because researchers have not considered the potential long-term positive effects of sustained activation of goal-irrelevant information. On the assumptions that most real-world environments are not random and that they entail regularity and predictability, processing of distraction at one point in time may well prove to have a sparing effect should the irrelevant information become relevant. If so, the present finding offers a dramatic example of one source of sustained performance by older adults outside of the laboratory.

\section{AUTHOR NOTE}

This research was supported by Grant R37 AGO4306 from the National Institute on Aging. We thank all the people who helped us in the data collection and entry processes of this project, including Jason Blevins, Ji-A Min, and many others. Correspondence concerning this article should be addressed to S. Kim or L. Hasher, Department of Psychology, University of Toronto, 100 St. George Street, Toronto, ON, M5S3G3 Canada (e-mail: shkim@psych.utoronto.ca, hasher@psych .utoronto.ca).

Note-Accepted by David A. Balota's editorial team.

\section{REFERENCES}

Adams, C., Smith, M. C., Pasupathi, M., \& Vitolo, L. (2002). Social context effects on story recall in older and younger women: Does the listener make a difference? Journals of Gerontology: Psychological Sciences, 57B, P28-P40.

Ansburg, P. I., \& Hill, K. (2003). Creative and analytic thinkers differ in their use of attentional resources. Personality \& Individual Differences, 34, 1141-1152.

BARnetT, S. M., \& CECI, S. J. (2002). When and where do we apply what we learn? A taxonomy for far transfer. Psychological Bulletin, 128, 612-637.

Carson, S. H., Peterson, J. B., \& Higgins, D. M. (2003). Decreased latent inhibition is associated with increased creative achievement in high-functioning individuals. Journal of Personality \& Social Psychology, 85, 499-506.

Chasteen, A. L., Bhattacharyya, S., Horhota, M., Tam, R., \& HASHER, L. (2005). How feelings of stereotype threat influence older adults' memory performance. Experimental Aging Research, 31, 235-260.

Cohn, N. B., Dustman, R. E., \& Bradford, D. C. (1984). Age-related decrements in Stroop Color Test performance. Journal of Clinical Psychology, 40, 1244-1250.

Connelly, S. L., Hasher, L., \& Zacks, R. T. (1991). Age and reading: The impact of distraction. Psychology \& Aging, 6, 533-541.

Craik, F. I. M., \& Salthouse, T. A. (EDS.) (2000). The handbook of aging and cognition (2nd ed.). Mahwah, NJ: Erlbaum.

Denney, N. W., \& Pearce, K. A. (1989). A developmental study of practical problem solving in adults. Psychology \& Aging, 4, 438-442.

DucheK, J. M., Balota, D. A., \& Thessing, V. C. (1998). Inhibition of visual and conceptual information during reading in healthy aging and Alzheimer's disease. Aging, Neuropsychology, \& Cognition, 5, 169-181.

Dywan, J., \& Murphy, W. E. (1996). Aging and inhibitory control in text comprehension. Psychology \& Aging, 11, 199-206.

Ekstrom, R. B., French, J. W., Harman, N. H., \& Dermen, D. (1976). Kit of factor-referenced cognitive tests (Rev. ed.). Princeton, NJ: Educational Testing Service.

Fry, A. F., \& Hale, S. (1996). Processing speed, working memory, and fluid intelligence: Evidence for a developmental cascade. Psychological Science, 7, 237-241.

Gazzaley, A., Cooney, J. W., Rissman, J., \& D'Esposito, M. (2005). Top-down suppression deficit underlies working memory impairment in normal aging. Nature Neuroscience, 8, 1298-1300.

Hamm, V. P., \& Hasher, L. (1992). Age and the availability of inferences. Psychology \& Aging, 7, 56-64.

Hasher, L., Lustig, C., \& ZaCKs, R. T. (in press). Inhibitory mechanisms and the control of attention. In A. R. A. Conway, C. Jarrold, M. J. Kane, A. Miyake, \& J. N. Towse (Eds.), Variation in working memory. Oxford: Oxford University Press.

Hasher, L., ZaCKs, R. T., \& MAY, C. P. (1999). Inhibitory control, circadian arousal, and age. In D. Gopher \& A. Koriat (Eds.), Attention and performance XVII: Cognitive regulation of performance. Interaction of theory and application (pp. 653-675). Cambridge, MA: MIT Press.

Hess, T. M., Rosenberg, D. C., \& Waters, S. J. (2001). Motivation and 
representational processes in adulthood: The effects of social accountability and information relevance. Psychology \& Aging, 16, 629-642.

Labouvie-VIEF, G. (1990). Modes of knowledge and the organization of development. In M. L. Commons, C. Armon, L. Kohlberg, F. A. Richards, T. A. Grotzer, \& J. Sinnott (Eds.), Adult development: Vol. 2. Models and methods in the study of adolescent and adult thought (pp. 43-62). New York: Praeger.

Lustig, C., Hasher, L., \& Tonev, S. T. (2006). Distraction as a determinant of processing speed. Psychonomic Bulletin \& Review, 13, 619-625.

MAY, C. P. (1999). Synchrony effects in cognition: The costs and a benefit. Psychonomic Bulletin \& Review, 6, 142-147.

May, C. P., \& Hasher, L. (1998). Synchrony effects in inhibitory control over thought and action. Journal of Experimental Psychology: Human Perception \& Performance, 24, 363-379.

May, C. P., Rahhal, T., Berry, E. M., \& Leighton, E. A. (2005). Aging, source memory, and emotion. Psychology \& Aging, 20, 571-578.

May, C. P., Zacks, R. T., Hasher, L., \& Multhaup, K. S. (1999). Inhibition in the processing of garden-path sentences. Psychology \& Aging, 14, 304-313.

McDowd, J. M., \& Oseas-Kreger, D. M. (1991). Aging, inhibitory processes, and negative priming. Journals of Gerontology: Psychological Sciences, 46, P340-P345.

Mednick, S. (1962). The associative basis of the creative process. Psychological Review, 69, 220-232.

PARK, D. C. (2000). The basic mechanisms accounting for age-related decline in cognitive function. In D. C. Park \& N. Schwarz (Eds.), Cognitive aging: A primer (pp. 3-21). Philadelphia: Psychology Press.

Rowe, G., Valderrama, S., Hasher, L., \& Lenartowicz, A. (2006). Attentional disregulation: A benefit for implicit memory. Psychology \& Aging, 21, 826-830.
Salthouse, T. A. (1996). The processing-speed theory of adult age differences in cognition. Psychological Review, 103, 403-428.

SMith, S. M., \& BlankenshiP, S. E. (1991). Incubation and the persistence of fixation in problem solving. American Journal of Psychology, 104, 61-87.

WeSt, R. (1999). Visual distraction, working memory, and aging. Memory \& Cognition, 27, 1064-1072.

\section{NOTE}

1. As in Connelly et al. (1991), there was no significant age difference in the number of words that intruded in reading stories with distraction $[t(50)=0.44]$.

\section{ARCHIVED MATERIALS}

The following materials associated with this article may be accessed through the Psychonomic Society's Norms, Stimuli, and Data archive, www.psychonomic.org/archive/.

To access this file, search the archive for this article using the journal (Psychonomic Bulletin \& Review), the first author's name (Kim) and the publication year (2007).

FILE: kim-PBR-2006.pdf

DESCRIPTION: The archive file contains the RAT materials.

AUTHOR’s E-MAIL ADDRESS: shkim@psych.utoronto.ca

(Manuscript received July 11, 2005; revision accepted for publication June 9, 2006.) 